\title{
AN INSTRUCTIONAL SCENARIO (LESSON PLAN): THE IMPORTANCE OF BREATHING. IS IT POSSIBLE WITHOUT BREATHING?
}

\author{
Eirini Vogiatzaki ${ }^{i}$, \\ Anastasia Nikolopoulou \\ Secondary School Teacher \\ 2nd Vocational High School of Heraklion, \\ 71409 Heraklion, \\ Crete, Greece
}

\begin{abstract}
:
This article aims to present a lesson plan entitled "The importance of breathing. Is it possible to live without breathing?" This lesson lasts for one teaching hour. It was carried out through the Cisco WebEx Meetings platform of modern training and concerns the course Nursing Theory II for the 3rd Class of Vocational High School (EPAL), specializing in Nursing Assistant in the Health, Welfare \& Wellness Sector. This script material was part of the training of B2 level ICT trainees, organized by the Institute of Educational Policy (IEP) with the co-financing of Greece and the European Union. The article aims to present a lesson plan so that students can deepen their knowledge in the thematic unit of Vital Signs with emphasis on the importance of breathing. More specifically, students learn to define what respiration is, to name and interpret the different types of respiration, but also to know when respirations should be counted. The strategy they relied on is collaborative learning. In particular, by organizing working groups, participation and interaction among students are enhanced. Students were asked to complete an interactive exercise created on e-me content, then worked on a collaborative document (Google forms) and completed a feedback quiz at the end of the lesson.
\end{abstract}

Keywords: breathing, types of breathing, training scenarios, nursing assistant

\section{Introduction}

Both theoretical knowledge and practical training by students, as well as the recording of all Vital Signs (temperature, respiration, arterial pulse, and blood pressure), play a particularly important role for all specialties of the Health, Welfare, and Wellness Sector (Gourgouli, et al., 2013). According to Gourgouli et al. (2013), "respiration is the uptake and utilization of oxygen and the production and elimination of carbon dioxide by cells and the body in general". The respiratory center that regulates respiration is located in the medulla

iCorrespondence: email vogiatzakirena@yahoo.gr 
oblongata. The process of breathing is achieved by respiratory movements, i.e. the inhaling and exhaling. Inhalation is performed actively, with the contraction of the respiratory muscles, while exhalation is performed passively, without their contraction. Once the inspiratory movement is over, the inspiratory muscles stop contracting and the chest returns to the position of calm exhalation (Gourgouli, et al., 2013). It is known that the vital points and one of them, which is breathing, occupy a central place in the Curriculum of the 3rd Grade of EPAL of the course "Nursing II, which intends to provide both in the theoretical and in the practice students in the laboratory (FEK 2292/vol.B/ 31/12/1999).

More specifically, the recourse to the theoretical knowledge of the thematic unit of respiration precedes the laboratory course and consequently the practical exercise, hence this article emphasizes the theoretical acquisition of knowledge, which will benefit in the correct diagnostic prediction and assessment of the condition of a patient/individual.

In the context of all this effort, the use of ICT is laying the foundation which contributes substantially, interactively, and pleasantly to the understanding and consolidation of what is to be taught, emphasizing the team spirit and collaboration of students (Matzagouras, 2000). The playful exercises, collaborative documents, and quizzes provided through ICTs help embed thrust the material being taught, and the Dumper for financing students, emphasizing the central points taught in the course and not too detailed or excess information, which can tire or confuse students. Also, the use of ICT enhances and encourages the active participation of students with learning difficulties and helps them to better consolidate the content of the lesson, but also to organize their notes more appropriately and to focus on all those important points of the lesson (Tsimpoukli, 1999). The role of the teacher is multifaceted and is on the side of all those students supporting, guiding, and strengthening their effort and in case of additional help is deemed necessary the teacher provides additional/explanatory and detailed material.

\section{Description of Educational Scenario}

The specific educational scenario lasts for one teaching hour (45 minutes) and concerns the course Nursing Theory II for the 3rd Class of Vocational High School (EPAL) specialty Nursing Assistant of the Health, Welfare \& Wellness Sector. All 14 students participated through the Cisco WebEx Meetings (modern education) platform created by the Ministry of Education, Research and Religions, due to the needs that arose due to Covid-19. No pre-existing knowledge is required regarding the topic taught to the students. However, a basic familiarity with the use of computers and software is required.

The learning objectives of the teaching scenario are distinguished into three levels. More specifically, on a cognitive level, the student should learn how to define breathing, name and interpret types of breathing, and mention when they have to take breaths. At the socio-emotional level, students actively participate in the activities during the lesson, discuss the results of the exercises, and evaluate how valuable learning one of 
the four Vital Signs of the human body, namely respiration, is. Finally, in terms of ICT use, they will become more familiar with distance education (Contemporary Education) and will approach ICT as tools and resources for interactive learning.

This teaching scenario emphasizes the active participation of students and the collaborative interaction of students. The strategy on which it was based is collaborative learning (Koulaidis, 2007). In particular, through working groups, participation and interaction with students are enhanced. ICT (Information and Communication Technology) educational applications tend to maximize the benefits of any type of course, whether it is to be implemented life in the classroom or remotely with modern or asynchronous education.

\section{Conclusions}

The evaluation of the students through the present educational scenario was positive, as both the purpose of the program and the individual teaching objectives were achieved. Through discussion that took place initially at the beginning of the course (modern education-Cisco WebEx Meetings), the students were allowed to exchange very interesting views and knowledge gained from personal experiences or experiences related to their close family environment. In the continuation of the lesson, they were given a collaborative document (Google forms), through which, they interacted with each other by commenting on each other's answers to the questions asked. After finishing their activities, the students completed a quiz aimed at understanding how well they had consolidated the knowledge they were taught. Shortly before the end of the course, there was time to discuss questions, but also to solve them. Besides, students became familiar with ICT (Information and Communication Technology) as the course was implemented through the Cisco WebEx Meetings platform (modern education), and all activities required the operation of a computer or tablet. Finally, the time of one teaching hour that was originally designed to implement the teaching scenario was sufficient for its successful completion.

\section{Conflict of Interest Statement}

The authors have no conflicts of interest to declare. We have seen and agreed with the contents of the manuscript and there is no financial interest to report. We certify that the submission is our original work and is not under review at any other publication and we have no commercial associations (e.g., consultancies, stock ownership, equity interest, patent/licensing arrangements, etc.) that might pose a conflict of interest in connection with the submitted article.

\section{Acknowledgments}

The Authors would like to express their gratitude to anyone who contributed in any way to the structuring, writing, and translating of this paper. Special thanks to Maria Protogeraki for her professional support and advice. 


\section{About the Authors}

Eirini Vogiatzaki (https://orcid.org/0000-0002-7676-2517) serves since 2017 as a secondary Level Teacher and an Adult Teacher Public Vocational Training Institute of Heraklion 1 \& 2.

Anastasia Nikolopoulou trains students from 2008 to 2014 \& from 2016 until today.

\section{References}

Gourgouli E., Kissoudi A., Lykostrati A., Petropoulou E. (2013). Nursing TheoryLaboratory. B class 1 st Staff LU, Health and Welfare (pp 72-73), Athens: Diofantos. Matzagouras, E.G. (2000). Collaborative teaching and learning. Athens: Grigoris.

Koulaidis, B. (2007). Modern Teaching Approaches for the Development of Criticism - Creative Thinking for Secondary Education. ОЕПЕК.

Tsimpoukli, Anna (1999). The training of special groups in Educational Methods - group of trainees. Vol. D, EAP, Patras.

FEK (2292/vol.B'/31/12/1999). Detailed curriculum for the courses of Health, Welfare \& Wellness, Nursing Theory II, Class of Daily Vocational High Schools (EPAL). 


\section{Annex 1}

\section{Screenplay Title}

An instructional scenario (lesson plan): the importance of breathing. Is it possible to live without breathing?

\section{Estimated duration of the teaching scenario}

1 teaching hour (45') distance using modern education.

Integration of the teaching scenario in the curriculum/prerequisite knowledge

Nursing Theory II 3rd Class EPAL Assistant Nursing in the Health, Welfare \& Wellness Sector.

\section{Prerequisite knowledge}

$\checkmark$ The students already have relevant knowledge of the taught thematic unit from the 2nd Grade of EPAL. They are not asked to repeat so that the teacher can assess what they remember and what they do not.

$\checkmark$ Basic knowledge of computers and software is required.

\section{Purpose and objectives of the teaching scenario}

Get to know one of the four vital points that are breathing.

The learning objectives of the teaching scenario are:

\section{Cognitive}

$\checkmark$ Learn the definition of breathing

$\checkmark$ Name and interpret the types of respiration

\section{Socio-emotional}

$\checkmark$ when breathing should be taken

$\checkmark$ Participate in the activities of the course

$\checkmark$ Discuss the results of the exercises

$\checkmark$ Assess the value of learning one of the four Vital Signs of the human body namely respiration

\section{Regarding the use of ICT}

$\checkmark$ Familiarity with distance education (Modern education)

$\checkmark$ Approaching ICT as tools and resources for interactive learning

\section{Supervisory means}

Both the teacher and the students should have either a Mobile or Tablet or laptop/ desktop computer, which has speakers, a camera, and a microphone. Internet connection is required. The teacher must have installed the Cisco WebEx meetings application, have a Google account for the use of Drive, and have codes of the Panhellenic School Network to be able to connect to e - me. Students must in turn have installed the Cisco WebEx 
meetings application, as well as have codes in the Panhellenic School Network to be able to connect to $\underline{\mathrm{e}-\mathrm{me}}$. The connection to the digital training platform can be made by clicking Cisco WebEx Meetings. The students have received the connection instructions on the e-classroom platform and a test connection has been made the day before.

\section{Description}

\section{Teaching method}

In this teaching scenario, emphasis is placed on the active participation of the students and the group interaction of the students. The educational ICT applications tend to maximize the benefits of each type of course whether it will be implemented SIA in person in the classroom or remotely with synchronous or asynchronous training.

\section{Class organization}

The online class consists of 14 students. In the implementation of the educational scenario, all the students of the 2nd grade of EPAL of the Health, Welfare \& Wellness Sector participate. At the beginning of the lesson, each student participates separately in the WebEx chat, by writing the answers to the questions asked. Then they complete the exercise that has been created in the e - me content and finally, they work in groups on worksheet 1 (Google documents) to complete their exercise, and finally, each of them completes a quiz after sharing the link given in the chat.

\section{ICT added value}

The lesson plan is entirely different from the form of modern education.

As a result, by using ICT, they provide:

1) Facilitation of communication, sharing, and interaction between students and their teacher

2) Interaction and immediate feedback from web applications

3) The added value from the use of new technologies lies in the multi-sensory approach of the specific skill and the multifaceted cognitive mobilization of the students.

4) With the use of new technologies both on theoretical and laboratory courses, a system of practice and practical application of knowledge by students is promoted, with the systematic guidance of the teacher.

\section{Teaching activities}

\section{Cognitive/psychological preparation activities (5 minutes)}

Students with the computer or tablet on will work individually and in groups remotely. The lesson begins with the question "what is breathing". Students are invited to compose the definition asked, with what already know. They will probably remember, to compose the definition in groups. The teacher then asks two more questions, "what are the types of breathing and what does each of them mean and" when should the breaths be taken". Again, students record what they remember in the chat of the same 
platform. Throughout this activity the teacher shares on WebEx a PowerPoint file he has prepared.

\section{Activity for the consolidation (25 minutes)}

The students, by using the above answers given in the WebEx chat and based on the teacher's questions, encourage students to go to the e-me, to do the corresponding interactive exercise (filling in the blanks) created by the teacher through the e - me content. To complete this exercise, students must log in to the wall of the Nursing Theory II course by clicking here. The teacher shares the above link with the students in the WebEx chat.

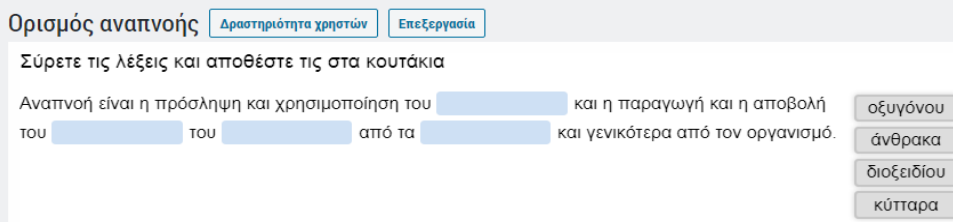

After completing the above exercise, students will deal with worksheet 1 (annex 2 ), where they will have to record the types of breaths and interpret each of them, as well as when the breaths should be taken.

\section{Evaluation Activity-Formative evaluation (10 minutes)}

By completing the above interactive exercise that has been created in the e - me content, as well as the exercises that exist in the collaborative Google document, students will need to complete a quiz as part of their assessment. The quiz is given from here (annex 3).

This is followed by a discussion by the students themselves, with the teacher intervening where necessary, and discussing the mistakes they made, getting the feedback they need.

\section{Use of PC, ICT, as well as other means for the teaching scenario}

Course wall Nursing Theory II DG Lyceum in e - me

Cisco WebEx Meetings Platform

PowerPoint presentation

E-me content

Quiz on Google forms

Collaborative document (Google forms)

Interactive book: http://ebooks.edu.gr/ebooks/handle/8547/3806 


\section{Final assessment of the course ( 5 minutes)}

At the end of the course the degree of achievement of the learning objectives of the teaching is evaluated through:

$\checkmark$ the completion of the quiz created by the teacher in Google forms

$\checkmark$ worksheet 1

$\checkmark$ the debate developed by students/behavior shows throughout the course and the chat of WebEx

\section{Worksheet}

Students are given to fill in worksheet 1 (Google forms) in groups. 


\section{Annex 2}

\section{Worksheet 1}

Course: Nursing Theory II

Class: 3rd Lyceum

Specialty: Nursing Assistant

After reading the book of Nursing, which you have already obtained from the beginning of the school year, pages $72 \& 73$ chapters 9 , subsection 9c and think about the question of when to take the breaths and the types of breaths, then do the following activity.

\begin{tabular}{|c|c|c|c|}
\hline Name & $\begin{array}{l}\text { Exercise 1: List the types of } \\
\text { respiration and their } \\
\text { definition }\end{array}$ & $\begin{array}{c}\text { Exercise 2: Record } \\
\text { when to take breaths }\end{array}$ & $\begin{array}{c}\text { Comment, add or } \\
\text { complete each other's } \\
\text { answer }\end{array}$ \\
\hline \multicolumn{4}{|c|}{ Konstantinos A. } \\
\hline \multicolumn{4}{|l|}{ Niki A. } \\
\hline \multicolumn{4}{|l|}{ Anthi A. } \\
\hline \multicolumn{4}{|l|}{ Maria B. } \\
\hline \multicolumn{4}{|l|}{ Popi Z. } \\
\hline \multicolumn{4}{|l|}{ Eirini K. } \\
\hline \multicolumn{4}{|l|}{ Valia K. } \\
\hline \multicolumn{4}{|l|}{ Maria K } \\
\hline \multicolumn{4}{|l|}{ Maria R. } \\
\hline \multicolumn{4}{|l|}{ Maria S. } \\
\hline \multicolumn{4}{|l|}{ Emanuel T. } \\
\hline \multicolumn{4}{|l|}{ Zacharias F. } \\
\hline \multicolumn{4}{|l|}{ Eirini Ch. } \\
\hline \multicolumn{4}{|l|}{ Eva T. } \\
\hline Emanuel T. & & & \\
\hline
\end{tabular}




\section{Annex 3}

Quiz: Types of breathing and when to take breaths

Student name:

1. The complete definition of respiration is

$\square$ The intake and utilization of oxygen and the production and elimination of carbon dioxide

$\square$ The intake and utilization of oxygen by cells and the body in general

$\square$ The intake and utilization of oxygen and the production and elimination of carbon dioxide and the body in general

(2 points)

2. The types of breathing are 4. Apnea, dyspnea, shortness of breath, and slowness.

True

False

3. Shortness of breath is the feeling of difficulty breathing

True

False

(2 points)

4. Apnea is sparse and shallow breathing

True

False

(2 points)

5. Sleep deprivation is the complete suppression of respiration

True

False

(2 points)

6. Shortness of breath is frequent and shallow breathing

True

False

(2 points)

7. Breathing should be taken 3 times a day when the patient is inhospital

True

False

(2 points) 
8. Breathing should be taken in patients with respiratory diseases

True

False

9. Breathing should be taken when the patient experiences cyanosis, dizziness, confusion, loss of consciousness

True

False

(2 points)

10. When we want to measure the patient's breathing, we must first inform him

True

False

(2 points) 
Creative Commons licensing terms

Authors will retain the copyright of their published articles agreeing that a Creative Commons Attribution 4.0 International License (CC BY 4.0) terms will be applied to their work. Under the terms of this license, no permission is required from the author(s) or publisher for members of the community to copy, distribute, transmit or adapt the article content, providing a proper, prominent and unambiguous attribution to the authors in a manner that makes clear that the materials are being reused under permission of a Creative Commons License. Views, opinions and conclusions expressed in this research article are views, opinions and conclusions of the author(s). Open Access Publishing Group and European Journal of Alternative Education Studies shal not be responsible or answerable for any loss, damage or liability caused in relation to/arising out of conflict of interests, copyright violations and inappropriate or inaccurate use of any kind content related or integrated on the research work. All the published works are meeting the Open Access Publishing requirements and can be freely accessed, shared, modified, distributed and used in educational, commercial and non-commercial purposes under a Creative Commons Attribution 4.0 International License (CC BY 4.0). 